\title{
Spark plasma sintering of damage tolerant and machinable YAM ceramics
}

\author{
Qian $\mathrm{WANG}^{a, b}$, Salvatore GRASSO ${ }^{c}$, Chunfeng $\mathrm{HU}^{a,{ }^{*}}$, Haibin $\mathrm{ZHANG}^{d}$, \\ Shu $\mathrm{CAI}^{b,{ }^{*}}$, Yoshio SAKKA ${ }^{e}$, Qing HUANG ${ }^{a,{ }^{*}}$ \\ ${ }^{a}$ Ningbo Institute of Materials Technology and Engineering (NIMTE), Chinese Academy of \\ Sciences (CAS), Ningbo 315201, China \\ ${ }^{b}$ Key Laboratory for Advanced Ceramics and Machining Technology of Ministry of Education, \\ Tianjin University, Tianjin 300072, China \\ ${ }^{c}$ School of Engineering \& Materials Science and Nanoforce Technology Ltd., Queen Mary \\ University of London, Mile End Road, London E1 4NS, UK \\ ${ }^{d}$ China Academy of Engineering Physics, Mianyang 621900, China \\ ${ }^{e}$ National Institute for Materials Science (NIMS), Tsukuba, Ibaraki 305-0047, Japan
}

Received: March 03, 2013; Revised: April 03, 2013; Accepted: April 04, 2013

OThe Author(s) 2013. This article is published with open access at Springerlink.com

\begin{abstract}
Single-phase $\mathrm{Y}_{4} \mathrm{Al}_{2} \mathrm{O}_{9}$ (YAM) powders were synthesized via solid-state reaction starting from nano-sized $\mathrm{Al}_{2} \mathrm{O}_{3}$ and $\mathrm{Y}_{2} \mathrm{O}_{3}$. Fully dense (99.5\%) bulk YAM ceramics were consolidated by spark plasma sintering (SPS) at $1800{ }^{\circ} \mathrm{C}$. We demonstrated the excellent damage tolerance and good machinability of YAM ceramics. Such properties are attributed to the easy slipping along the weakly bonded crystallographic planes, resulting in multiple energy dissipation mechanisms such as transgranular fracture, shear slipping and localized grain crushing.
\end{abstract}

Keywords: ceramic; synthesis; microstructure; property; damage tolerance

\section{Introduction}

In the $\mathrm{Al}_{2} \mathrm{O}_{3}-\mathrm{Y}_{2} \mathrm{O}_{3}$ phase diagram, three intermediate compounds exist: (i) $\mathrm{Y}_{3} \mathrm{Al}_{5} \mathrm{O}_{12}$ (YAG) with cubic yttrium aluminum garnet structure, (ii) $\mathrm{YAlO}_{3}$ (YAP) with orthorhombic yttrium aluminum perovskite or hexagonal structure, and (iii) $\mathrm{Y}_{4} \mathrm{Al}_{2} \mathrm{O}_{9}$ (YAM) with monoclinic structure [1]. YAG has been widely investigated for a wide range of applications, including rare-earth doped phosphors [2-6] (where color and

* Corresponding authors.

E-mail: Chunfeng Hu, hucf@nimte.ac.cn;

Shu Cai, caishu@tju.edu.cn;

Qing Huang, huangqing@nimte.ac.cn efficiency are controlled by host lattice effects), and transparent ceramics for solid-state lasers [7-9]. In addition, more structural applications have been proposed for YAG as reinforcement fiber in ceramics and intermetallic composites [10] besides functional YAG thermal barrier coatings (TBC) [11] and thin films $[12,13]$.

Compared to YAG, YAP shows complementary properties, and it is currently employed in laser system as an excellent gain medium material for scintillators, acousto-optics [14,15] and Q-switches [16,17].

Up to now, the luminescence properties of rare-earth doped YAM have been widely investigated. For example, Yadav et al. [18] studied the emitting properties of $\mathrm{Eu}^{3+}$-doped YAM exposed to vacuum 
ultraviolet (VUV) and ultraviolet (UV). Wang and Wang [19] reported that YAM:Re $\left(\operatorname{Re}=\mathrm{Tb}^{3+}, \mathrm{Eu}^{3+}\right)$ phosphors are promising candidates for plasma display applications. The thermal stability and phase transformation of YAM at high temperature attract considerable research attention as well [20-24]. Furthermore, YAM might have some potential applications even as high-temperature oxidation/ thermal barrier coatings [25]. In fact, Zhan et al. [26] have shown that the lattice thermal conductivity of YAM is as low as $1.10 \mathrm{~W} /(\mathrm{m} \cdot \mathrm{K})$ on the basis of the first-principles calculation, and experimental results confirme a very low thermal conductivity of $1.56 \mathrm{~W} /(\mathrm{m} \cdot \mathrm{K})$ at $1000{ }^{\circ} \mathrm{C}$.

However, despite the significant number of scientific publications about YAM, its intrinsic mechanical properties are seldom described in literature. The present work aims to (i) synthesize high-purity single-phase YAM powders via a solid-state reaction, (ii) achieve fully dense bulk ceramics using spark plasma sintering (SPS), and (iii) characterize the microstructure and describe the mechanisms involved in its damage tolerance behavior and machinability.

\section{Experimental procedure}

Nano $\mathrm{Al}_{2} \mathrm{O}_{3}$ powders $(140 \mathrm{~nm}, \quad 99.99 \%$, Taimei Chemcials Co Ltd., Osaka, Japan) and nano $\mathrm{Y}_{2} \mathrm{O}_{3}$ powders $(50 \mathrm{~nm}, 99.99 \%$, Aladdin Reagent Inc., Shanghai, China) with the molar ratio of $1: 2$ were wet mixed in a planetary ball milling machine. The slurry was freeze-dried in order to minimize particle agglomeration. Subsequently, the freeze-dried powders were sieved and heated in an alumina crucible at $1650{ }^{\circ} \mathrm{C}$ for $30 \mathrm{~h}$ by using a muffle furnace (Nabertherm P310, Bremen, Germany). The as-synthesized powder mixture was poured in a $20-\mathrm{mm}$ diameter graphite mould and densified by an SPS furnace (FCT Systeme GmbH DH25, Frankenblick, Germany). The densification process was carried out via a multi-step heating method; the initial heating rate from room temperature (RT) to $1300{ }^{\circ} \mathrm{C}$ was $50{ }^{\circ} \mathrm{C} / \mathrm{min}$, and at higher temperature it was reduced down to $25^{\circ} \mathrm{C} / \mathrm{min}$. The dwell time and uniaxial pressure were $15 \mathrm{~min}$ and $30 \mathrm{MPa}$, respectively. The sintered bulks were examined by X-ray diffraction (XRD, Bruker AXS Inc. D8 Discover, Madison, WI) and scanning electron microscope (SEM, Hitachi S-4800, Tokyo, Japan) equipped with energy dispersive spectrum
(EDS). The densities of sintering polished bodies were determined by Archimedes method. Vickers hardness $\left(H_{\mathrm{v}}\right)$ was measured by a Vickers hardness tester (Wilson Wolpert 432 SVD, Norwood, MA, USA) under various loads. For each load, six indents were made. The morphologies of indents were examined by SEM. The polished and fractured surfaces were also examined with SEM. The flexure strength was determined via a three-point bending test. The samples were cut into the dimensions of $3 \mathrm{~mm} \times 3 \mathrm{~mm} \times 18 \mathrm{~mm}$ with diamond wire saw. The crosshead in the test was $0.5 \mathrm{~mm} / \mathrm{min}$. The brittleness index $(B)$ and $\mathrm{CNC}$ (computer numerical control) machining were used to quantitatively estimate the machinability of YAM ceramics. The thermal conductivity of disk YAM specimen $(\Phi 12.7 \mathrm{~mm} \times 1 \mathrm{~mm})$ was measured by the laser flash technique in the temperature range of $400-980{ }^{\circ} \mathrm{C}$. At various temperatures, the thermal conductivity $\left(D_{\text {th }}\right)$ and constant pressure molar heat capacity $\left(C_{\mathrm{p}}\right)$ were measured by a laserflash thermal analyzer (NETZSCH LFA457, Selb, Germany).

\section{Results and discussion}

The synthesis of YAM powders was carried out via a solid-state reaction using nano-sized $\mathrm{Al}_{2} \mathrm{O}_{3}$ and $\mathrm{Y}_{2} \mathrm{O}_{3}$ powders as starting materials. The relatively high reaction temperature $\left(1650{ }^{\circ} \mathrm{C}\right)$ and prolonged dwelling time $(30 \mathrm{~h})$ contributed to the synthesis of pure YAM powders as confirmed by XRD.

The starting $\mathrm{Al}_{2} \mathrm{O}_{3}$ is $\alpha$ phase, which is the only allotrope thermodynamically stable at high temperature [27]. In addition, $\mathrm{Al}^{3+}$ and $\mathrm{Y}^{3+}$ show identical valence. Thus, no electron migration occurred in the reaction process; the reaction was mainly driven by the mutual diffusion of $\mathrm{Al}^{3+}$ and $\mathrm{Y}^{3+}$ ions. However, the ionic radius of $\mathrm{Y}^{3+}$ ion is larger than that of $\mathrm{Al}^{3+}$ ion, making the solid-state reaction largely depending on the diffusion rate of $\mathrm{Y}^{3+}$ ion. Therefore, it is reasonable to assume that the reaction kinetics was mainly controlled by the diffusion rate of $\mathrm{Y}^{3+}$ ions into $\mathrm{Al}^{3+}$-rich side.

During the progress of the reaction, YAM, YAP and YAG phases appeared (detected by XRD, not shown here). The intermediated formed phases behaved as barrier inhibiting the mutual diffusion of $\mathrm{Al}^{3+}$ ions and $\mathrm{Y}^{3+}$ ions. Accordingly, in comparison with the phase-diagram temperatures, the formation of intermediate layers required higher reaction 
temperature and prolonged soaking time to complete the synthesis of YAM.

Due to the thermal stability even at $1650{ }^{\circ} \mathrm{C}$ for tens of hours (experimental synthesis conditions), in combination with the extremely low thermal conductivity [26], YAM might be considered as a promising candidate for thermal insulation material. In order to investigate the mechanical properties of YAM ceramics, the as-prepared powders were consolidated by SPS method. Figure 1 shows the XRD pattern of YAM bulk sintered at $1800{ }^{\circ} \mathrm{C}$ for $15 \mathrm{~min}$. No phase transformation or decomposition is observed in comparison with the starting powders, and all the diffraction peaks belong to YAM phase.

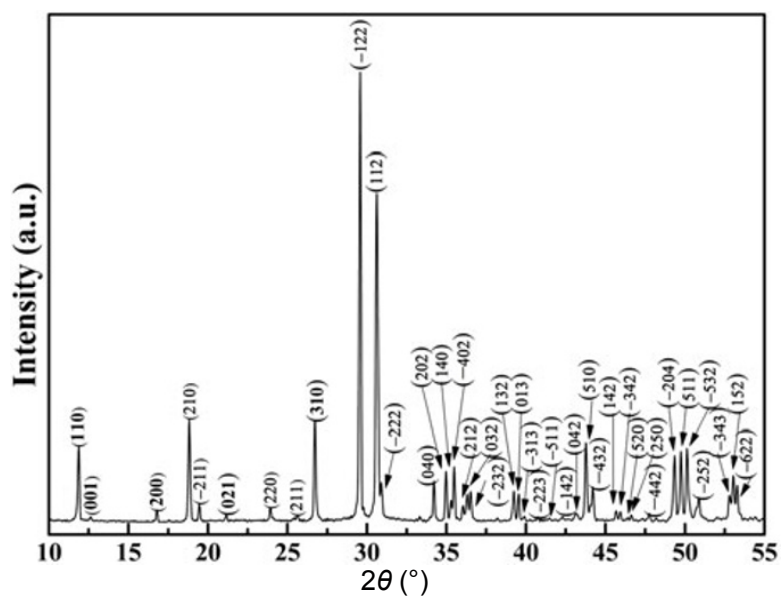

Fig. 1 XRD pattern of YAM bulk sintered at $1800{ }^{\circ} \mathrm{C}$ for $15 \mathrm{~min}$. No detectable modification on the pattern is observed in comparison with the synthesized powders.

Figure 2 shows the absolute and relative densities of sintered YAM bulk as a function of SPS temperatures. The densities increase with the increment of sintering temperature. Full dense YAM, $99.5 \%\left(4.497 \mathrm{~g} / \mathrm{cm}^{3}\right)$, is obtained when the sintering temperature is $1800{ }^{\circ} \mathrm{C}$. No phase decomposition is observed in the YAM, thus confirming the excellent temperature stability even up to $1800{ }^{\circ} \mathrm{C}$.

Figure 3 shows the SEM micrographs of polished and fracture surfaces of YAM ceramics sintered at $1750{ }^{\circ} \mathrm{C}$ and $1800{ }^{\circ} \mathrm{C}$. As confirmed in Figs. 3(a) and 3 (b), no obvious porosity is observed on the polished surfaces, and this is consistent with the density measurements shown in Fig. 2. As observed in Figs. $3(\mathrm{c})$ and 3(d), the main fracture mode is transgranular. In addition, typical cleavage zone pointed by an arrow

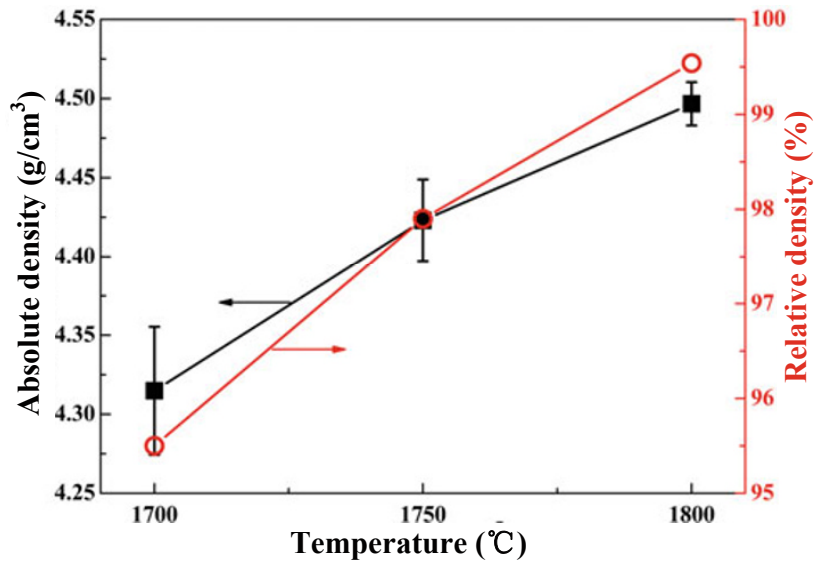

Fig. 2 Absolute and relative densities of sintered YAM bulk as a function of sintering temperatures.

in Fig. 3(c) is found widely distributed on the fracture surfaces. The specific fracture surface also indicates the presence of weak interface. Sun et al. [28] reported the similar fracture characteristic in high damage tolerant ceramics $\gamma-\mathrm{Y}_{2} \mathrm{Si}_{2} \mathrm{O}_{7}$, where the fracture energy was believed to be consumed by crack deflection and cleavage. Similarly, the YAM fracture by cleavage is a more preferred means for energy dissipation since it requires less energy than crack propagation through the grain boundaries [29].

The insets of Fig. 4 show the Vickers hardness imprints of YAM performed under different indentation loads. Due to the elastic recovery of the sample during unloading, the so-called indentation size effect (ISE) [30] occurs and the Vickers hardness decrease with the load. The Vickers hardness of dense YAM ceramics under a load of $100 \mathrm{~N}$ approaches $4.3 \mathrm{GPa}$.

From the insets of Fig. 4, no cracks are generated at the corner of the indents for loads between $10 \mathrm{~N}$ and $100 \mathrm{~N}$. The mechanical feedback behaviors of YAM to external loads imply that some special energy dissipation mechanisms might exist there. Consequently, the morphology of Vickers indentation imprints was investigated with SEM. It is found at a low load $(10 \mathrm{~N})$, the indentation energy is dissipated by grain crushing. When the load is increased up to $30 \mathrm{~N}$, apart from being absorbed by grain crushing, the mechanical energy is directly dissipated at the contact area by the shearing slipping (Fig. 4 Inset (b)). When the loads are increased up to $50 \mathrm{~N}$ and $100 \mathrm{~N}$, the contact pressure zones peel off the material from the surfaces, and this might be associated with pulling out and sliding effects induced by the high shearing stress. 

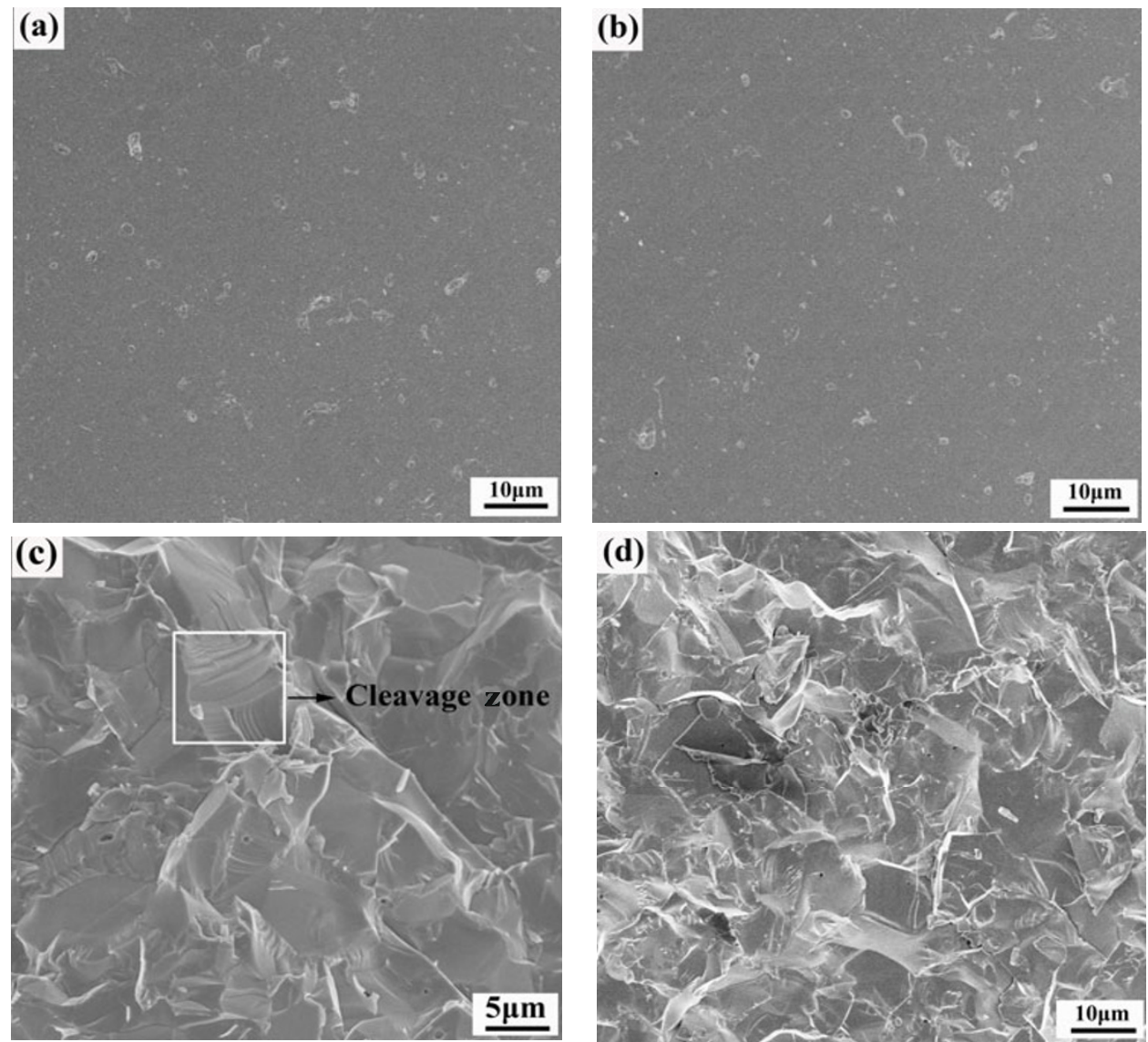

Fig. 3 SEM micrographs of polished surfaces (sintered at (a) $1750{ }^{\circ} \mathrm{C}$, (b) $1800{ }^{\circ} \mathrm{C}$ ) and fracture morphologies (sintered at (c) $1750{ }^{\circ} \mathrm{C}$, (d) $1800{ }^{\circ} \mathrm{C}$ ) of YAM bulks.

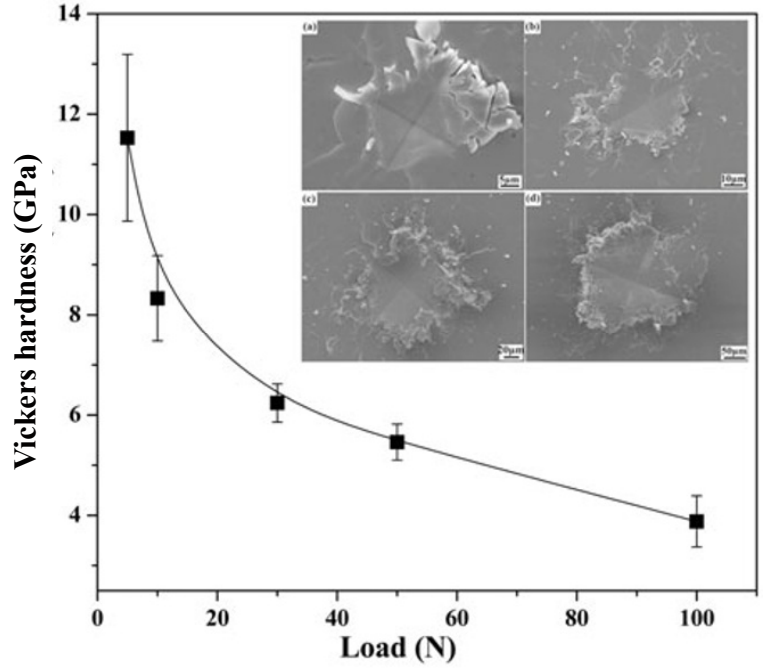

Fig. 4 Vickers hardness profile as a function of indentation load. The insets show the SEM micrographs of Vickers indents induced by different loads: (a) $10 \mathrm{~N}$, (b) $30 \mathrm{~N}$, (c) $50 \mathrm{~N}$, and (d) $100 \mathrm{~N}$.

The obvious protuberance observed along the edges of the imprints as evidenced in Fig. 4 Insets (c) and (d), suggests that the weakly bonded planes easily slip under the shear stress of the indentations [26]. The damage mechanisms consist of intergranular and transgranular fractures, grain crushing and pulling-out effect. It is then reasonable to conclude that YAM ceramics exhibit typical damage tolerant features like $\gamma-\mathrm{Y}_{2} \mathrm{Si}_{2} \mathrm{O}_{7}$ and nano-layered MAX phases [28,31].

In order to investigate in more details the damage mechanisms involved, the cross section of indentation imprint made by a load of $50 \mathrm{~N}$ was analyzed. As indicated in Fig. 5(a), three layers distribute vertically downward to the damage zone, being surface layer, subsurface layer and substrate, respectively. It is observed that the surface layer is crushed into fine powders. Grain crushing is believed to be the dominating mechanism for energy dissipation. Together with grain crushing (Fig. 5(b), area B), it is possible to observe shear slipping (Fig. 5(c), area C) in the subsurface layer. As also evidenced in Fig. 5, the substrate remains intact, while most of the indentation energy is locally dissipated nearby the indentation by crushing and shearing of grains. This localized dissipating energy feature is comparable with contact 
damage tolerance of quasi-plastic ceramics such as MAX phases [31].
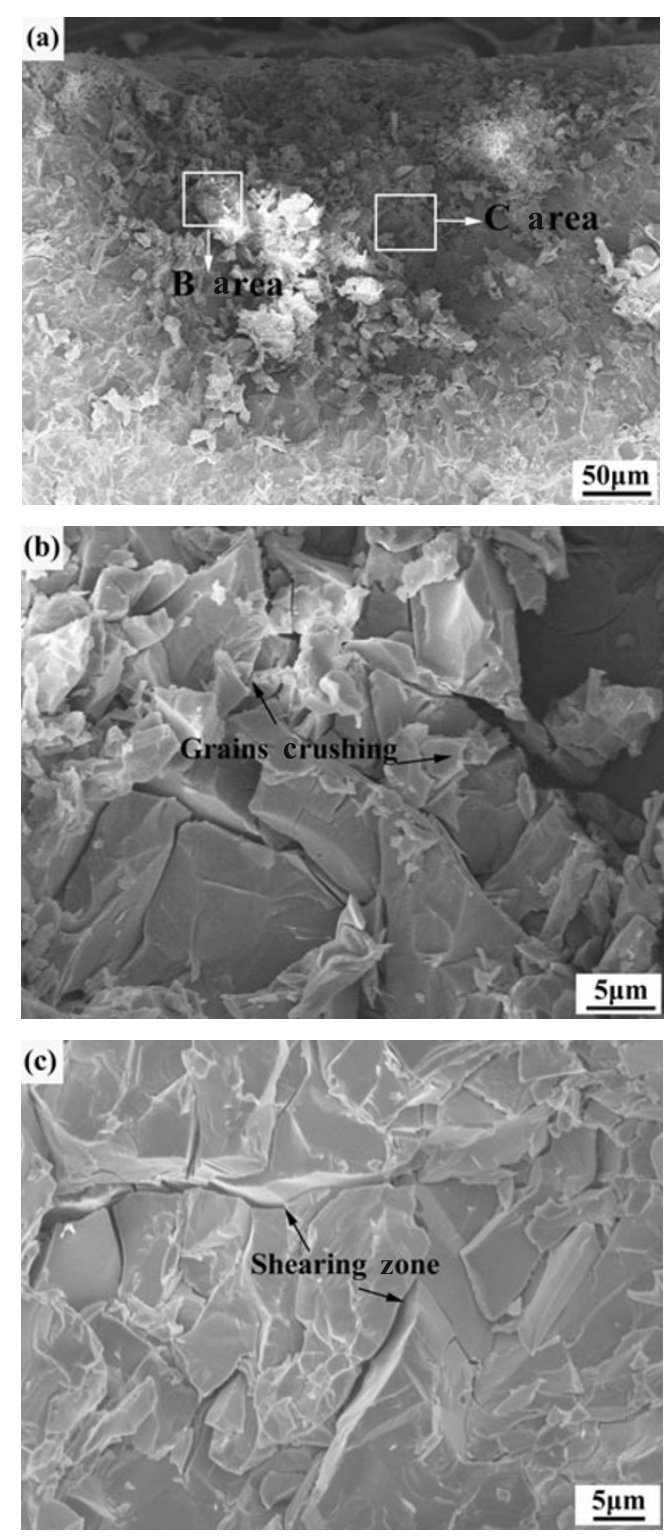

Fig. 5 (a) Magnification of protruded zone, evidencing (b) grain crushing (area B in (a)), and (c) shear zone (area $\mathrm{C}$ in (a)) obtained under an indentation load of $100 \mathrm{~N}$ of YAM sintered at $1800{ }^{\circ} \mathrm{C}$.

It is also found that dense bulk YAM ceramics can be easily machined by conventional cemented carbide (WC-Co) drill. Drilling test was performed using a $3-\mathrm{mm}$ diameter drill with a rotating speed of $1250 \mathrm{rpm}$. No drilling fluid or coolant was used during the drilling. YAM ceramics show almost the same material removal rate compared to MAX phases. A macrograph of the drilled sample with 3 closely aligned holes is shown in Fig. 6(a). The holes couple well with the drill, no visible cracking or chipping phenomena are observed around these holes. A high-magnification SEM image to the inner wall of the drilled hole is shown in Fig. 6(b). The inner wall of the hole is complanate and partially covered with a layer of smeared debris. The apparent roughness $\left(R_{\mathrm{a}}\right)$ is about $4 \mu \mathrm{m}$. Consequently, it is then reasonable to consider YAM as machinable ceramics. Although porosity, to some degree, determines the machinability of ceramics greatly [32], it is just not the case for YAM ceramics when considering the extremely high relative density of sintered bulks. The cleavage planes that behave as weak interfaces in fact partially contribute to the good machinability, as demonstrated in the case of mica-containing machinable glass ceramics [33]. Analogously, the successful fabrication of machinable $\mathrm{Si}_{3} \mathrm{~N}_{4} / \mathrm{h}$-BN composite is also benefitting from the self-possessing cleavage planes in h-BN [34,35]. In addition, the aforementioned specific energy dissipation mechanisms such as grain crushing, shear slipping or deflection and branching effects might as well contribute to the machinalibity of YAM ceramics.
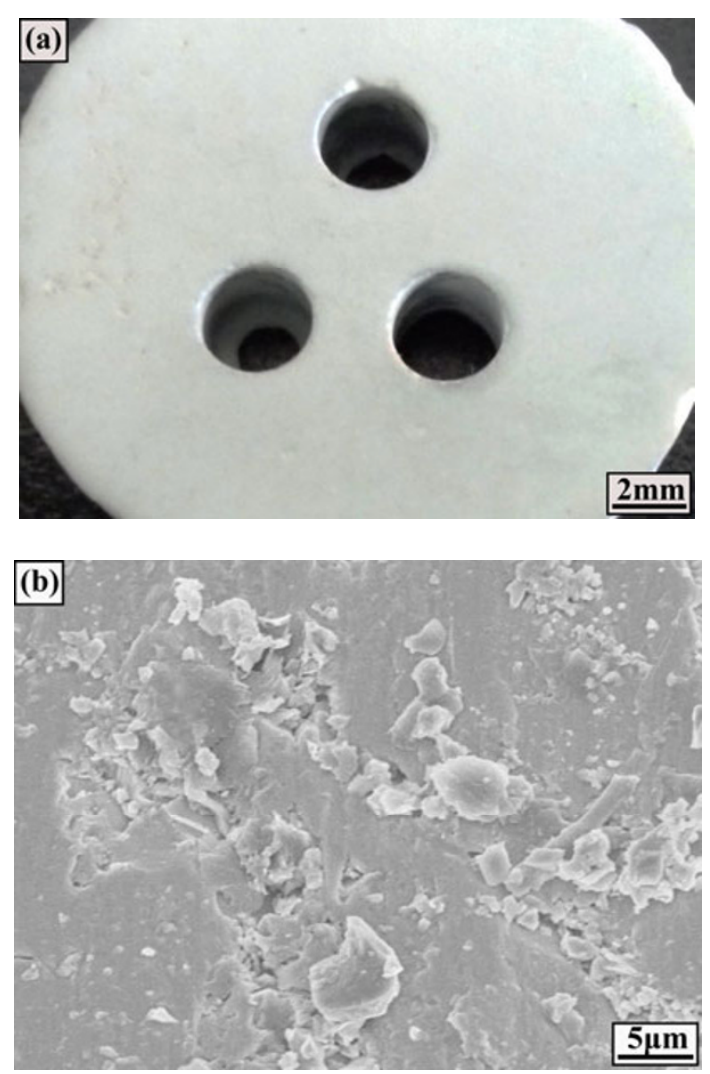

Fig. 6 (a) Optical photograph of the drilled YAM ceramics and (b) SEM image of the surface of the drilled hole. 
First-principles calculations anticipate that YAM exhibits relative low shear modulus (74 GPa) [28]. The flexure strength of dense YAM ceramics prepared by SPS is $110 \mathrm{MPa}$. In agreement with the previous investigations on machinable oxide ceramics such as $\mathrm{LaPO}_{4}$ [36] and $\mathrm{CaWO}_{4}$ [37], both the low shear modulus and shear strength are crucial factors to obtain good machinability. Thus, the relative low shear modulus together with the low flexure strength of YAM might also have led to the good machinability.

Furthermore, brittleness index $(B)$, originally introduced by Boccaccini [38], is used to quantitatively assess the machinability of YAM. The brittleness index $(B)$ is defined as follows:

$$
B=\frac{H_{\mathrm{V}}}{K_{\mathrm{IC}}}
$$

where $H_{\mathrm{V}}$ represents the intrinsic Vickers hardness; $K_{\mathrm{IC}}$ stands for the fracture toughness. Lower value of $B$ corresponds to the superior machinability. For comparison, some typical machinable ceramics such as $\mathrm{LaPO}_{4}$ [36], Macor [39], $\mathrm{Ti}_{3} \mathrm{SiC}_{2}$ [40], $\mathrm{Nb}_{4} \mathrm{AlC}_{3}$ [41], and $\gamma-\mathrm{Y}_{2} \mathrm{Si}_{2} \mathrm{O}_{7}$ [28] are listed in Table 1. As indicated in Table 1, the brittleness index of YAM is $3.58 \mu \mathrm{m}^{-1 / 2}$, while for highly machinable MAX phases of $\mathrm{Ti}_{3} \mathrm{SiC}_{2}$ and $\mathrm{Nb}_{4} \mathrm{AlC}_{3}$, the $B$ values are $0.67 \mu \mathrm{m}^{-1 / 2}$ and $0.37 \mu^{-1 / 2}$, respectively. Even if YAM does not show machinability as good as that of MAX phases, the machinability of YAM is comparable to $\gamma-\mathrm{Y}_{2} \mathrm{Si}_{2} \mathrm{O}_{7}$ ceramics and it is slightly better than that of $\mathrm{LaPO}_{4}$ ceramics.

Table 1 The calculated brittleness indexes of typical ceramics

\begin{tabular}{cccc}
\hline & Vickers hardness $H_{\mathrm{v}}(\mathrm{GPa})$ & Fracture toughness $K_{\mathrm{IC}}\left(\mathrm{MPa} \cdot \mathrm{m}^{1 / 2}\right)$ & Brittleness index $B\left(\mu \mathrm{m}^{-1 / 2}\right)$ \\
\hline $\mathrm{LaPO}_{4}[36]$ & 4.86 & 1.0 & 4.86 \\
$\mathrm{Macor}[39]$ & 3.00 & 1.4 & 2.14 \\
$\mathrm{Ti}_{3} \mathrm{SiC}_{2}[40]$ & 4.00 & 6.0 & 0.67 \\
$\mathrm{Nb}_{4} \mathrm{AlC}_{3}[41]$ & 2.60 & 7.1 & 0.37 \\
$\gamma-\mathrm{Y}_{2} \mathrm{Si}_{2} \mathrm{O}_{7}[28]$ & 6.20 & 2.1 & 2.95 \\
$\mathrm{YAM}$ & 4.30 & $1.2[26]$ & 3.58 \\
\hline
\end{tabular}

As shown in Fig. 7, due to the potential application as TBC at high temperature, we measured the heat capacity and thermal conductivity of YAM up to $980{ }^{\circ} \mathrm{C}$. The thermal conductivity of YAM ceramics slightly increases between $400{ }^{\circ} \mathrm{C}$ and $600{ }^{\circ} \mathrm{C}$. In this temperature range, the dominant thermal conduction mechanism is phonon thermal conduction. In the temperature range between $600{ }^{\circ} \mathrm{C}$ and $980{ }^{\circ} \mathrm{C}$, the contribution of photon thermal conduction becomes

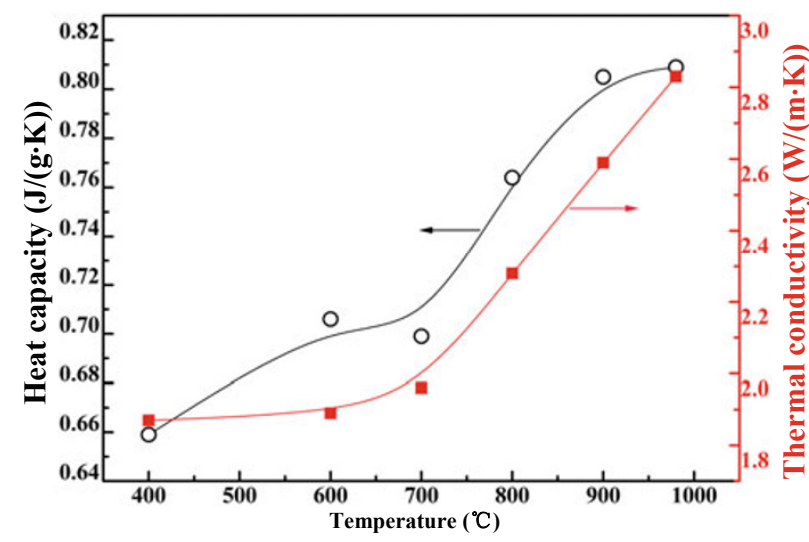

Fig. 7 Experimental measurements of heat capacity and thermal conductivity of the as-prepared YAM ceramics sintered at $1800{ }^{\circ} \mathrm{C}$. significant. The thermal conductivity of dense YAM is $2.83 \mathrm{~W} /(\mathrm{m} \cdot \mathrm{K})$ at $980{ }^{\circ} \mathrm{C}$. The higher thermal conductivity compared with that ever reported by Zhan et al. [26] might be attributed to different morphology in local and the way of material preparation. The relatively low thermal conductivity together with excellent high temperature stability make YAM ceramics a promising candidate for TBC materials. As a comparison, the thermal conductivity of YAM is comparable to that of the widely-known TBC material-yttria-stabilized zirconia (YSZ, $2.0 \mathrm{~W} /(\mathrm{m} \cdot \mathrm{K})$ at $1127{ }^{\circ} \mathrm{C}$ [11]), while thermal stability of the former is definitely much better. As for YAG, another stable phase in the $\mathrm{Y}_{2} \mathrm{O}_{3}-\mathrm{Al}_{2} \mathrm{O}_{3}$ system with a thermal conductivity of $3.2 \mathrm{~W} /(\mathrm{m} \cdot \mathrm{K})$ at $1000{ }^{\circ} \mathrm{C}$, has been proposed as potential TBC materials [11]. Consequently, from this point of view, YAM might even have slight superiority over YAG in TBC material field.

\section{Conclusions}

Single-phase $\mathrm{Y}_{4} \mathrm{Al}_{2} \mathrm{O}_{9} \quad$ (YAM) powders were successfully synthesized by a solid-state reaction 
carried out at $1650{ }^{\circ} \mathrm{C}$ for $30 \mathrm{~h}$ starting from nano-sized $\mathrm{Al}_{2} \mathrm{O}_{3}$ and $\mathrm{Y}_{2} \mathrm{O}_{3}$ particles. Full dense YAM ceramics were obtained in a subsequent SPS consolidation step. When the SPS sintering temperature was $1800{ }^{\circ} \mathrm{C}$, the relative density of sintered body was as high as 99.5\%. Fracture morphologies revealed the predominance of transgranular fracture mode. The intrinsic Vickers hardness of YAM was $4.3 \mathrm{GPa}$. The flexure strength of dense YAM ceramics was $110 \mathrm{MPa}$. It was confirmed that YAM ceramics were damage tolerant and machinable. The intergranular and transgranular energy dissipation mechanisms for crack propagation involved grain crushing and grain shear slipping. The thermal conductivity of YAM was $2.83 \mathrm{~W} /(\mathrm{m} \cdot \mathrm{K})$ at $980{ }^{\circ} \mathrm{C}$.

\section{Acknowledgements}

The present work was supported by "Chunlei Program" in Ningbo, "Hundred Talents Program" of the Chinese Academy of Sciences (No. KJCX2-EW-H06), National Natural Science Foundation of China (No. 51172248/E020301), and National Natural Science Foundation of China (Nos. 50772072 and 51072129).

Open Access: This article is distributed under the terms of the Creative Commons Attribution Noncommercial License which permits any noncommercial use, distribution, and reproduction in any medium, provided the original author(s) and source are credited.

\section{References}

[1] Abell JL, Harris IR, Cockayne B, et al. An investigation of phase stability in the $\mathrm{Y}_{2} \mathrm{O}_{3}-\mathrm{Al}_{2} \mathrm{O}_{3}$ system. J Mater Sci 1974, 9: 527-537.

[2] Xia GD, Zhou SM, Zhang JJ, et al. Structural and optical properties of YAG: $\mathrm{Ce}^{3+}$ phosphors by sol-gel combustion method. J Cryst Growth 2005, 279: 357-362.

[3] Won CW, Nersisyan HH, Won HI, et al. Efficient solid-state route for the preparation of spherical YAG:Ce phosphor particles. J Alloys Compd 2011, 509: 2621-2626.

[4] Rai P, Song M-K, Song H-M, et al. Synthesis, growth mechanism and photoluminescence of monodispersed cubic shape Ce doped YAG nanophosphor. Ceram Int 2012, 38: 235-242.

[5] Zhu QQ, Hu WW, Ju LC, et al. Synthesis of $\mathrm{Y}_{3} \mathrm{Al}_{5} \mathrm{O}_{12}: \mathrm{Eu}^{2+}$ phosphor by a facile hydrogen iodide-assisted sol-gel method. J Am Ceram Soc 2013, 96: 701-703.

[6] Song HJ, Noh JH, Roh H-S, et al. Preparation and characterization of nano-sized $\mathrm{Y}_{3} \mathrm{Al}_{5} \mathrm{O}_{12}: \mathrm{Ce}^{3+}$ phosphor by high-energy milling process. Curr Appl Phys 2013, DOI: 10.1016/j.cap.2013.01.033.

[7] Dong J, Shirakawa A, Ueda K, et al. Efficient $\mathrm{Yb}^{3+}: \mathrm{Y}_{3} \mathrm{Al}_{5} \mathrm{O}_{12}$ ceramic microchip lasers. Appl Phys Lett 2006, 89: 091114.

[8] Zhang WX, Zhou J, Liu WB, et al. Fabrication, properties and laser performance of Ho:YAG transparent ceramic. J Alloys Compd 2010, 506: 745-748.

[9] Qin XP, Yang H, Zhou GH, et al. Fabrication and properties of highly transparent Er:YAG ceramics. Opt Mater 2012, 34: 973-976.

[10] Fabrichnaya O, Seifert HJ, Ludwig T, et al. The assessment of thermodynamic parameters in the $\mathrm{Al}_{2} \mathrm{O}_{3}-\mathrm{Y}_{2} \mathrm{O}_{3}$ system and phase relations in the Y-Al-O system. Scand J Metall 2001, 30: 175-183.

[11] Su YJ, Trice RW, Faber KT, et al. Thermal conductivity, phase stability, and oxidation resistance of $\mathrm{Y}_{3} \mathrm{Al}_{5} \mathrm{O}_{12} \quad(\mathrm{YAG}) / \mathrm{Y}_{2} \mathrm{O}_{3}-\mathrm{ZrO}_{2}$ (YSZ) thermalbarrier coatings. Oxid Met 2004, 61: 253-271.

[12] Chao W-H, Wu R-J, Wu T-B. Structural and luminescent properties of YAG:Ce thin film phosphor. J Alloys Compd 2010, 506: 98-102.

[13] Wu Y-C, Parola S, Marty O, et al. Structural characterizations and waveguiding properties of YAG thin films obtained by different sol-gel processes. Opt Mater 2005, 27: 1471-1479.

[14] Shim JB, Yoshikawa A, Nikl M, et al. Scintillation properties of the $\mathrm{Yb}$-doped $\mathrm{YAlO}_{3}$ crystals. Radiat Meas 2004, 38: 493-496.

[15] Medraj M, Hammond R, Parvez MA, et al. High temperature neutron diffraction study of the $\mathrm{Al}_{2} \mathrm{O}_{3}-\mathrm{Y}_{2} \mathrm{O}_{3}$ system. $J$ Eur Ceram Soc 2006, 26: 3515-3524.

[16] Su H, Shen HY, Lin WX, et al. Computational model of Q-switch Nd:YAlO 3 dual-wavelength laser. J Appl Phys 1998, 84: 6519.

[17] Sullivan AC, Wagner GJ, Gwin D, et al. High power Q-switched Tm: $\mathrm{YAlO}_{3}$ lasers. Advanced Solid-State Photonics, Santa Fe, New Mexico, February 1, 2004: WA7.

[18] Yadav R, Khan AF, Yadav A, et al. Intense red-emitting $\mathrm{Y}_{4} \mathrm{Al}_{2} \mathrm{O}_{9}: \mathrm{Eu}^{3+}$ phosphor with short decay time and high color purity for advanced 
plasma display panel. Opt Express 2009, 17: 22023-22030.

[19] Wang DY, Wang YH. Photoluminescence of $\mathrm{Y}_{4} \mathrm{Al}_{2} \mathrm{O}_{9}: \mathrm{Re}\left(\mathrm{Re}=\mathrm{Tb}^{3+}, \mathrm{Eu}^{3+}\right)$ under VUV excitation. $J$ Alloys Compd 2006, 425: L5-L7.

[20] Toropov NA, Bondar IA, Galadhov FY, et al. Phase equilibria in the yttrium oxide-alumina system. Russ Chem B+ 1964, 13: 1076-1081.

[21] Yamane H, Omori M, Okubo A, et al. High-temperature phase transition of $\mathrm{Y}_{4} \mathrm{Al}_{2} \mathrm{O}_{9} . J \mathrm{Am}$ Ceram Soc 1993, 76: 2382-2384.

[22] Yamane H, Omori M, Hirai T. Twin structure of $\mathrm{Y}_{4} \mathrm{Al}_{2} \mathrm{O}_{9}$. J Mater Sci Lett 1995, 14: 561-563.

[23] Yamane H, Shimada M, Hunter BA. Hightemperature neutron diffraction study of $\mathrm{Y}_{4} \mathrm{Al}_{2} \mathrm{O}_{9}$. J Solid State Chem 1998, 141: 466-474.

[24] Mah T-I, Keller KA, Sambasivan S, et al. High-temperature environmental stability of the compounds in the $\mathrm{Al}_{2} \mathrm{O}_{3}-\mathrm{Y}_{2} \mathrm{O}_{3}$ system. $\mathrm{J}$ Am Ceram Soc 1997, 80: 874-878.

[25] Yang S, Lan X, Huang N. Role of $\mathrm{Y}_{4} \mathrm{Al}_{2} \mathrm{O}_{9}$ in high temperature oxidation resistance of $\mathrm{NiCoCrAlY}-\mathrm{ZrO}_{2} \cdot \mathrm{Y}_{2} \mathrm{O}_{3}$ coatings. $J$ Mater $\mathrm{Sci}$ Technol 2007, 23: 568-570.

[26] Zhan X, Li Z, Liu B, et al. Theoretical prediction of elastic stiffness and minimum lattice thermal conductivity of $\mathrm{Y}_{3} \mathrm{Al}_{5} \mathrm{O}_{12}, \mathrm{YAlO}_{3}$ and $\mathrm{Y}_{4} \mathrm{Al}_{2} \mathrm{O}_{9} . J \mathrm{Am}$ Ceram Soc 2012, 95: 1429-1434.

[27] López-Delgado A, Fillali L, Jiménez JA, et al. Synthesis of $\alpha$-alumina from a less common raw material. J Sol-Gel Sci Technol 2012, 64: 162-169.

[28] Sun ZQ, Zhou YC, Wang JY, et al. $\gamma-\mathrm{Y}_{2} \mathrm{Si}_{2} \mathrm{O}_{7}$, a machinable silicate ceramic: Mechanical properties and machinability. J Am Ceram Soc 2007, 90: 2535-2541.

[29] Mecholsky Jr. JJ, Freimam SW, Rice RW. Fracture surface analysis of ceramics. J Mater Sci 1976, 11: 1310-1319.

[30] Gao H, Huang Y, Nix WD, et al. Mechanism-based strain gradient plasticity-I. Theory. J Mech Phys
Solids 1999, 47: 1239-1263.

[31] Bao YW, Hu CF, Zhou YC. Damage tolerance of nanolayer grained ceramics and quantitative estimation. Mater Sci Tech-Long 2006, 22: 227-230.

[32] Padture NP, Evans CJ, Xu HHK, et al. Enhenced machinalibity of silicon carbide via microstructural design. J Am Ceram Soc 1995, 78: 215-217.

[33] Baik DS, No KS, Chun JSS, et al. Mechanical properties of mica glass-ceramics. J Am Ceram Soc 1995, 78: 1217-1222.

[34] Wang RG, Wei P, Jiang MN, et al. Investigation of the physical and mechanical properties of hot-pressed machinable $\mathrm{Si}_{3} \mathrm{~N}_{4} / \mathrm{h}-\mathrm{BN}$ composites and FGM. Mat Sci Eng B 2002, 90: 261-268.

[35] Wang RG, Wei P, Chen J, et al. Fabrication and characterization of machinable $\mathrm{Si}_{3} \mathrm{~N}_{4} / \mathrm{h}-\mathrm{BN}$ functionally graded materials. Mater Res Bull 2002, 37: 1269-1277.

[36] Morgan PED, Marshall DB. Ceramic composites of monazite and alumina. J Am Ceram Soc 1995, 78: 1553-1563.

[37] Mogilevsky P, Parthasarathy TA, Petry MD. Anisotropy in room temperature microhardness and fracture of $\mathrm{CaWO}_{4}$ scheelite. Acta Mater 2004, 52: 5529-5537.

[38] Boccaccini AR. Machinability and brittleness of glass-ceramics. J Mater Process Tech 1997, 65: 302-304.

[39] Davis JB, Marshall DB, Housley RM, et al. Machinable ceramics containing rare-earth phosphates. J Am Ceram Soc 1998, 81: 2169-2175.

[40] Wang XH, Zhou YC. Microstructure and properties of $\mathrm{Ti}_{3} \mathrm{AlC}_{2}$ prepared by the solid-liquid reaction synthesis and simultaneous in-situ hot pressing process. Acta Mater 2002, 50: 3143-3151.

[41] $\mathrm{Hu} \mathrm{CF}$, Li FZ, He LF, et al. In situ reaction synthesis, electrical and thermal, and mechanical properties of $\mathrm{Nb}_{4} \mathrm{AlC}_{3}$. J Am Ceram Soc 2008, 91: 2258-2263. 